\title{
EĞiTiME GiRiş
}

Editör:

Doç. Dr. Halük Ünsal 


\title{
EĞiTiME GiRiş
}

Editör: Doç. Dr. Halük Ünsal

\author{
Yayın No. : : 2915 \\ Eğtim No.: : 619 \\ ISBN : : 978-625-406-342-8 \\ E-ISBN : : 978-625-406-341-1 \\ Basım Sayısı : 1. Basım, Ekim 2020
}

(c) Copyright 2020, NOBEL AKADEMİK YAYINCILIK EĞiTİM DANIŞMANLIK TİC. LTD. ŞTİ. SERTİFIKA NO.: 40340

Bu baskının bütün hakları Nobel Akademik Yayıncılık Eğitim Danıșmanlık Tic. Ltd. Ști.ne aittir. Yayınevinin yazılı izni olmaksızın, kitabın tümünün veya bir kısmının elektronik, mekanik ya da fotokopi yoluyla basımı, yayımı, çoğaltımı ve dağıtımı yapılamaz.

Nobel Yayın Grubu, 1984 yılından itibaren ulusal ve 2011 yılından itibaren ise uluslararası düzeyde düzenli olarak faaliyet yürütmekte ve yayınladığı kitaplar, ulusal ve uluslararası düzeydeki yükseköğretim kurumları kataloglarında yer almaktadır.

Genel Yayın Yönetmeni : Nevzat Argun -nargun@nobelyayin.com-

Yayın Koordinatörü : Gülfem Dursun -gulfem@nobelyayin.com-

Redaksiyon : Seda Çelikkaya -seda@nobelyayin.com-

Sayfa Tasarım : Leyla Kurt -leyla@nobelyayin.com-

Kapak Tasarım : Mehtap Yürümez -mehtap@nobelyayin.com-

Baskı Sorumlusu: Yavuz Şahin -yavuz@nobelyayin.com-

Baskı ve Cilt : : Atalay Matbaacıllik / Sertifika No.: 15689-

Büyük Sanayi 1 Cad. Elif Sok. No.:7/236-237 İskitler / ANKARA

\section{Kütüphane Bilgi Kartı}

\section{Ünsal, Halük.}

Eğitime Giriș / Editör: Doç. Dr. Halük Ünsal

1. Basım. XXII +578 s. $16 \times 23,5 \mathrm{~cm}$. Kaynakça var, dizin yok.

ISBN : :978-625-406-342-8

E-ISBN : 978-625-406-341-1

$\begin{array}{lll}\text { 1.Eğitim } & \text { 2. Ögretmen } & \text { 3. Eğitim Bilimi }\end{array}$

\section{Genel Dağıtım}

ATLAS AKADEMIK BASIM YAYIN DAĞITIM TIC. LTD. ŞTí.

Adres: Bahçekapı mh. 2465 sk. Oto Sanayi Sitesi No:7 Bodrum Kat Şaşmaz-ANKARA - siparis@nobelyayin.com-

Telefon: +90 3122785077 - Faks: 03122782165

E-Satış: www.nobelkitap.com - www.atlaskitap.com - Bilgi: esatis@nobelkitap.com - info@atlaskitap.com

Dağııım ve Satıs Noktaları: Alfa Basım Dağıım, Arasta, Arkadaş Kitabevi, D\&R Mağazaları,

Dost Dağıım, Ekip Dağııım, Kida Dağııım, Kitapsan, Nezih Kitabevleri, Pandora, Prefix, Remzi Kitabevleri 


\section{IÇiNDEKILER}

BÖLÜM YAZARLARI ............................................................... II

\section{BÖLÜM 1 \\ EĞITIMIN TEMEL KAVRAMLARI}

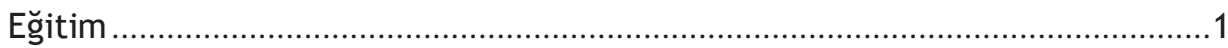

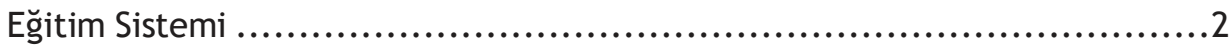

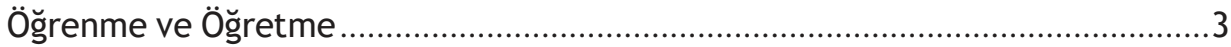

Öğretim Stratejisi............................................................

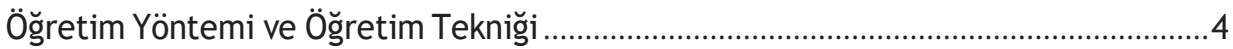

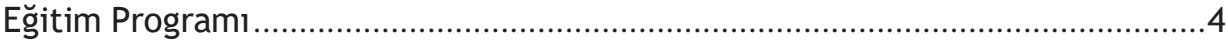

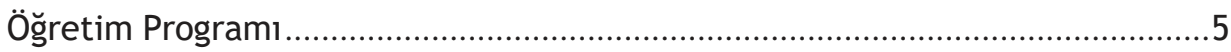

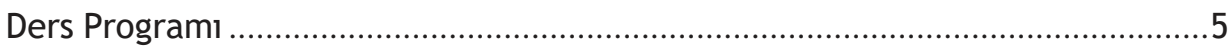

Gizli (Örtük) Program ..................................................6

Kültür (Kültürleme, Kültürlenme, Kültürleșme) .......................................................................................6

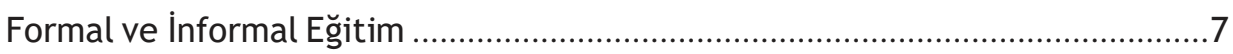

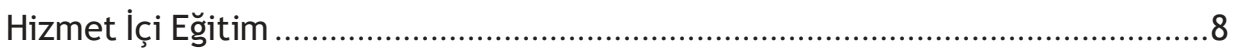

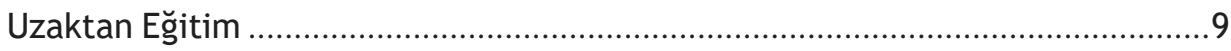

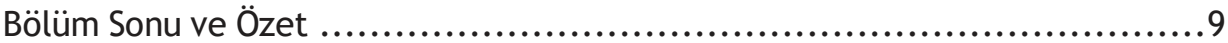

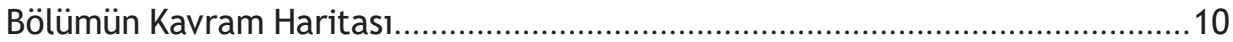

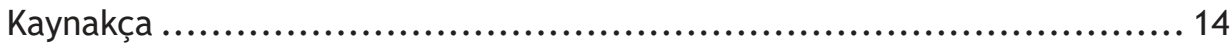

\section{BÖLÜM 2 \\ EĞiTiMiN IŞLEVLERi}

Giriș

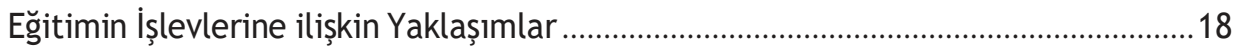

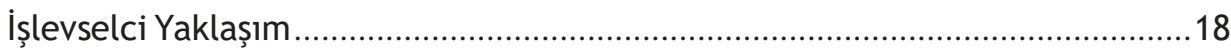




\title{
B Ö L Ü M \\ 10
}

\section{EĞiTiMDE ARAŞTIRMA YÖNTEMLERI}

\author{
Ayfer Sayın
}

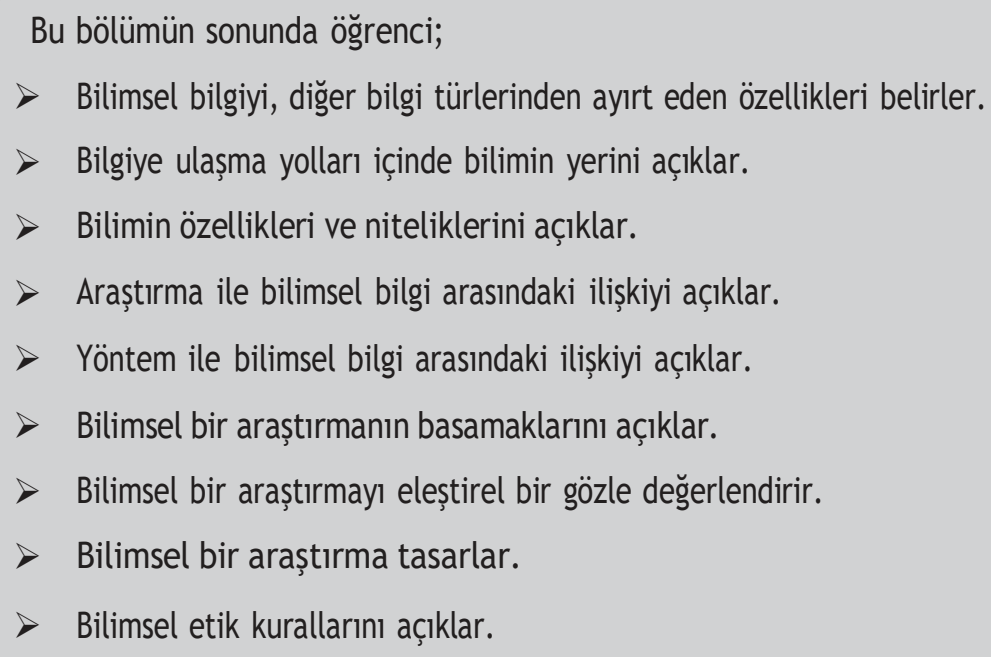

Bu bölüme bir bilmece ile başlayalım:

Gerçekten görebildiğimiz bir şey değil. Kesinlikle dokunamaz, tadamaz, duyamaz veya koklayamayı. Yine de ne zaman baksak oradadır, dikkat çekmek için uğraştığımız her yerde onu kullanabiliriz. Onu bir kitabın sayfalarında, sabah gazetesinde veya videonun ekranının parlayan ışıklarda bulabiliriz. Bilim insanları onun genlerimizde ve yağmur ormanının yemyeşil karmaşıklığında depolandığını söylüyorlar. Vatikan Kütüphanesinde 


\section{KAYNAKÇA}

Abd-El Khalick, F., \& Lederman, N.G. (2000). The influence of history of science cour- ses on students views of nature of science. Journal of Research in Science Teaching, 37(10),1057- 1095.

American Education Research Association (AERA). (2006). Standards for reporting on empirical social science research in AERA publications. Educational Researcher, 35(6): 33-40..

Başkale, H. (2016). Nitel araştırmalarda geçerlik, güvenirlik ve örneklem büyüklüğü- nün belirlenmesi. Dokuz Eylül Üniversitesi Hemşirelik Fakültesi Elektronik Dergisi, 9(1), 23-28. .

Berg, L. Bruce, \& Lune, H. (2016). Qualitative research methods for the social sciences. (Çev. Arı, A., 2019). Sosyal bilimlerde nitel araştırma yöntemleri. Konya: Eğitim Kitabevi.

Büyüköztürk, Ş. (2013). Sosyal bilimler için veri analizi el kitabı. Ankara: Pegem Akademi Yayınları.

Büyüköztürk, Ş., Çakmak, E. K., Akgün, Ö. E., Karadeniz, Ş., \& Demirel, F. (2010). Bilimselaraştırma yöntemleri. Ankara: Pegem Akademi Yayınları.

Cohen, L., Manion, L., \& Morrison, K. (2005). Research methods in education. (5th Ed.). London: Routledge Falmer.

Collins, K. M. T., Onwuegbuzie, A. J., \& Jiao, Q. G. (2006). Prevalence of mixed-methods sampling designs in social science research. Evaluation \& Research in Education, 19(2), 83-101.

Cooper, H. M. (1988). Organizing knowledge synthesis: a taxonomy of literature reviews. Knowledge in Society, 1, 104-126. https://venngage.net/p/4581/coopers-taxonomy.

Creswell, J. W. (2014). Research design: qualitative, quantitative, and mixed methods approaches. (4the Ed.) California: Sage Publications.

Çelik, F. (2011). İlköğretim 4. ve 5. sınıf öğrencilerinin öğrenme stilleri ile ders çalışma alışkanlıkları arasındaki ilişkilerin incelenmesi (Yüksek Lisans Tezi, Marmara Üniversitesi, İstanbul). Erişim adresi: http://tez2.yok.gov.tr/

Çepni, S. (2008). Fen ve teknoloji öğretimi kuramdan uygulamaya. Ankara: Pegem Akademi Yayınları.

Daştan, A., Bayraktar, Y., \& Bellikli, U. (2019). Türkiye'de sosyal bilimler alanında bilimsel araştırma ve yayın etiği eğitimi: İdeali arayış bağlamında bir araştırma. Global Journal of Economics and Business Studies, 8 (15) , 21-39.

Erdem, A. R. (2012), Bilim insanı yetiştirmede etik eğitimi. Yükseköğretim ve Bilim Dergisi, 2(1), 25-32. DOI: 10.5961/jhes.2012.030

Frankel, J. R. \& Wallen, N. E. (2009). How to design and evaluate research in education. (7thEd.). New York, NY: McGraw-Hill International Edition.

Kaptan, S. (1998). Bilimsel araştırma ve istatistik teknikleri. Ankara: Bilim Yayınevi. Karasar, N. (2008). Bilimsel araştırma yöntemleri. İstanbul: Nobel Yayın Dağıtım.

Karataş, Z. (2015). Sosyal bilimlerde nitel araştirma yöntemleri. Manevi 
Temelli Sosyal Hizmet Araştırmaları Dergisi, 11(1), 62-80.

Kırbaş, D., \& Çevik, F. (2017). Bilimsel Araştırma Yöntemleri ve Araştırma Etiği. (1th Ed.). İstanbul: Nobel Tıp Kitabevleri.

Laugksch, R., C. (2000). Scientific literacy: A conceptual overview. Science Education, 84(1), 71-94.

Lederman, N. G., \& Lederman, J. S. (2004). Revising instruction to teach nature of scien-ce. The Science Teacher, 71(9), 36-39.

Leshan, L. (1942). The breaking of a habit by suggestion during sleep. The Journal of Abnor- maland Social Psychology, 37(3), 406-408.

Patton, M. Q. (1990). Qualitative evaluation and research methods. (2th Ed.). London: Sage Publications.

Paul, R. (1996). Critical thinking: What every person needs to survive in rapidly changing world. USA:Foundation for critical thinking.

Şimşek, H., \& Yıldırım, A. (2005). Sosyal bilimlerde nitel araştırma yöntemleri. (5th Ed.)Ankara: Seçkin Yayıncılık.

Tonta, Y. (1999). Bilgi Toplumu ve Bilgi Teknolojisi. Türk Kütüphaneciliği. 13(4): 363-375. Türk Dil Kurumu (TDK) (2020). Güncel Türkçe sözlüğü. Erişim adresi: https://sozluk.gov. tr/

Türnüklü, A. (2001). Eğitim bilim alanında aynı araştırma sorusunu yanıtlamak için farklıaraştırma tekniklerinin birlikte kullanılması. Eğitim ve Bilim, 26(120), 8-13.

Ünal, M., Toprak, M., \& Baspinar, V. (2012). Bilim etiğine aykırı davranışlar ve yaptırım-lar: Sosyal ve beşerî bilimler için bir çerçeve önerisi. Amme İdaresi Dergisi, 45(3), 1-27.

Yardımcı, A. B. (2019). Bilim ve sözde bilim: Bilimsel topluluğun doğasının belirlenmesi ve sözde bilimin ayırt edilmesine yönelik sosyal bir ölçüt. Kaygı. Uludağ Üniversitesi Fen-Edebiyat Fakültesi Felsefe Dergisi, 18(2), 567-588.

Yaşar, Şefik (1998). Çağdaş bilim anlayışı. G. Can (Ed.). Çağdaş yaşam çağdaş insan içinde. (ss. 153-160). Eskişehir: Anadolu Üniversitesi Açıköğretim Fakültesi Yayınları.

Webster, F. (1996). The information society: Conceptions and critique. A. Kent (Ed.) Ency- clopedia of library and information science içinde (ss. 74112). New York: Marcel Dekker.

Yıldırım, A. (1999). Nitel araştırma yöntemlerinin temel özellikleri ve eğitim araştırmalarındaki yeri ve önemi. Eğitim ve Bilim, 23(112), 7-17.

Yıldırım, A., \& Şimşek, H. (2008). Sosyal Bilimlerde Nitel Araştırma Yöntemleri (6th Ed.). Ankara: Seçkin Yayıncılık. 